\title{
Imagens no feminino
}

\author{
Maria João Brilhante
}

0 portefólio de imagens que aqui se apresenta constitui uma selecção de retratos de actrizes portuguesas, preparada para uma exposição que ocorreu na Faculdade de Letras da Universidade de Lisboa no âmbito do colóquio 0 feminino no teatro organizado por investigadoras do Centro de Estudos de Teatro, em Março de 2014.

Como selecção que é, obedeceu à definição prévia de alguns critérios que foram emergindo das questões colocadas a um acervo de imagens muito mais vasto. Que se queria então mostrar através do conjunto das fotografias seleccionadas? Actrizes que se dispuseram a ser fotografadas, que procuraram, através da produção de imagens suas em contextos e momentos diferentes das suas vidas, criar uma identidade artística e/ou pessoal e divulgá-la, por diversos meios, junto a conhecidos e desconhecidos que, desse modo, acreditavam deter um fragmento dessa identidade.

"O retrato, nas classificações académicas a partir do Renascimento, faz parte da 'pintura de História', género nobre por excelência [...]", escreve José Augusto França (1981: 7), e acrescenta que a representação do modelo (no nosso caso, a actriz) é, muitas vezes, pretexto do retrato e da arte de retratar. Na verdade, é nessa dialéctica entre retrato referido a um modelo identificável e retrato que existe na autonomia do seu sistema de signos estéticos que podemos abordar a criação e a representação retratística.

0 fotógrafo capturou nas imagens uma figuração parcial da actriz e contribuiu, não raras vezes, para inventar a sua singularidade e para construir o vínculo entre a actriz e o destinatário, e fê-lo através de um complexo conjunto de códigos artísticos estabelecidos e de convenções sociais que, por seu turno, agirão sobre a padronização vigente.

Os retratos deste portefólio dizem-nos, mesmo através de uma observação rápida, que o corpo feminino e os seus modos de representação sofreram alterações notáveis. Podemos classificá-los e arrumá-los em categorias discutiveis (retrato oficial, o actor em representação ou em personagem, retrato à civil, retrato alegórico), colocar em evidência alguns tópicos para a sua análise (tipologia de teatro, temas como a erotização do corpo, o papel social do actor, a teatralidade da imagem, entre outros) ou cruzá-los com informação histórica disponivel sobre o fotógrafo, o suporte material ou o conteúdo representado. Todavia, será sempre a ambiguidade - ou o equívoco, como diz José Augusto França - que prenderá o nosso olhar a estes retratos. Modelos mortos ou ainda vivos converteram-se em fragmentos da história do teatro por via da iconicidade das representações imagéticas. 0 que fizeram, o que mostraram de si nos palcos ou na vida está perdido; as suas imagens dizem, como Jorge Silva Melo, "Bem sei que não existimos, os que nos acendemos e apagamos pela noite. Fomos, somos, só assim sombras que nos vamos." (2002)

Mas, ainda assim, satisfaz-nos olhar para estas imagens e encontrar as poses de Beatriz Costa citando Louise Brooks na boina e na franja, transformando-se, em seguida, em actriz melodramática à maneira de Judy Garland, empenhada em construir uma "carreira" paralela à dos palcos no estúdio fotográfico, pela mão de fotógrafos que absorviam os códigos da fotografia de cinema ou de Harcourt (Silva Nogueira, por exemplo). Mas se recuarmos no tempo, descobrimos Palmira Bastos em personagem, primeiro como jovem actriz que começara no teatro ligeiro, e a mesma, quase no final de um longo percurso no teatro sério ("declamado"), em pose oficial, olhando-nos do lugar da grande senhora do teatro nacional. E que dizer dos retratos joviais e confiantes de Mercedes Blasco, de Teresa Gomes, de Mirita Casimiro, de Mariana Vilar, de Alma Flora, de Laura Alves, com os seus olhares para fora do retrato, a cabeça ligeiramente erguida e banhada pela luz?

Mostrar o corpo e torná-lo desejado pelo(a) consumidor(a) da imagem requer um tratamento plástico que passa pela escolha daquilo que se mostra - o colo, as costas, o corpo inteiro - e do modo como se mostra furtiva ou explicita e arrojadamente. E aí temos Augusta Cordeiro em amazona, Clara Baptista de ombros roliços, Etelvina Serra, mostrando as costas num ousado decote, em 1917, e Laura Alves, em maillote pose revisteira e atrevida. Por outro lado, vestir-se de homem não era apenas um recurso dramatúrgico ancestral, era essencialmente uma maneira de desafiar os códigos de género: mulheres de calças, sabemos que só no palco, até Coco Chanel ter saido para a rua em calça-casaco. Neste conjunto incluimos Palmira Bastos em A gata borralheira, a jovem Laura Alves contracenando com Ivone Nogueira em desafiadora pose masculina (com as pernas bem separadas), o mesmo podendo ser dito de Beatriz Costa de mãos nos bolsos e farto bigode e, em 1909, de Ângela Pinto imitando Sarah Bernardt no papel de Hamlet.

Deixo para o leitor a tarefa de interrogar o que significam para a construção identitária imagens das nossas actrizes, à civil, desempenhando os seus papéis sociais: Amélia Rey Colaço cumprimentando Salazar ou abraçando a filha, Adelina e Aura Abranches, mãe e filha, vendo passar o funeral de D. João da Câmara ou posando sorridentes e cúmplices para a câmara da Fotografia Portugália, enquanto, anos mais tarde (1964), Eunice Muñoz recebe o Prémio da Imprensa, no II Festival Internacional de Teatro da Cidade de Lisboa. 
Por último, destaco dois possiveis conjuntos: um de mais óbvio interesse teatral, mas também mais arriscado pela sua dimensão enganadora; outro de maior poder simbólico e afectivo na comunicação com o observador. No primeiro conjunto, temos os retratos que pretendem fixar a actriz e o seu desempenho: quer através das personagens a que deu corpo, casos de Emília das Neves homenageada por Manuel de Macedo e Caetano Alberto nas páginas da revista Ocidente, em 1884, de Amélia Rey Colaço fotografada por José Marques em 1963 e no começo da sua carreira em 0 caso do dia, ou ainda de Carmen Dolores, captada por Pedro Soares na peça Balanceada; quer através da exposição dos seus dotes histriónicos, como nos mostram Palmira Bastos, em 1906, em expressões referidas à peça A viúvinha e Ângela Pinto graças a um friso de expressões faciais cómicas, fotografada por Pinto Marinho. Quanto ao segundo conjunto, ele é constituído por todas as imagens que retratam as actrizes como actrizes, isto é, representando simbolicamente, e fora de qualquer "papel", a sua natureza artística, como parecem revelar as fotografias de Maria Clementina, Brunilde Júdice, Maria Alice, Amélia Rey Colaço (Royal Foto), Glicinia Quartin, Eunice Munõz (José Marques), e Maria Lalande (Horácio Novais), muitas vezes modelos cúmplices dos seus fotógrafos, grandes fotógrafos, também eles inscrevendo na imagem a sua singularidade artistica, em debate com as contingências sociais e ideológicas da criação.

\section{Referências bibliográficas}

FRANÇA, José Augusto (1981), O retrato na arte portuguesa, Lisboa, Livros Horizonte.

MELO, Jorge Silva (2002), "Um teatro que não existiu, o nosso", Público, 23 de Fevereiro, p. 4.

Legendas

1> Palmira Bastos, s.d., Fotografia Brasil, TNDMII,

Pose: foto artistica.

2> Eunice Muñoz, s.d., fot. José Marques, MNT, Pose: foto artistica.

3> Mirita Casimiro, s.d., fot. não identificado, MNT Pose: foto artistica.

4> Glicínia Quartin, s.d., fot. José Marques, MNT, Pose: foto artistica.

5> Amélia Rey Colaço, s.d., fot. Royal Foto, MNT, Pose: foto artistica.

6> Maria Benard, s.d., fot. Silva Nogueira, MNT, Pose: foto artistica.

7> Brunilde Júdice, s.d.fot. não identificado, TNDMII, Pose: foto artistica.

8> Etelvina Serra, s.d., Álbum Teatral, vol. II, 1917, Pose: foto artistica.

9> Maria Lalande, s.d., Estúdio Horácio Novais, FCG, Pose: foto artistica.

10> Maria Clementina, s.d., Fotografia Brasil, TNDMII, Pose: foto artistica.

$11>$ Augusta Cordeiro, s.d., fot. não identificado, TNDMII, Pose: corpo e sensualidade.

12> Ângela Pinto em Hamlet, 1909, fot. Cardoso \& Correia, TNDMII, Pose: corpo e sensualidade. 13> Laura Alves, s.d., fot. Auliano, MNT, Pose: corpo e sensualidade.
14> Clara Baptista, s.d., fot. não identificado, TNDMII, Pose: corpo e sensualidade

15> Palmira Bastos em A Gata Borralheira, s.d., col. postais "Theatro", 126, TNDMIII, Pose: corpo e sensualidade. 16> Ângela Pinto, s.d., aut. Pires Marinho, BrasilPortugal, 01-04-1902, Pose: personagem.

17> Amélia Rey Colaço em 0 caso do dia, s.d. (1926?), fot. não identificado, MNT, Pose: personagem. 18> Amélia Rey Colaço, em La Contesssa,1963, fot. José Marques, MNT, Pose: personagem.

19> Carmen Dolores em Balanceada, s.d., fot. Pedro Soares, MNT, Pose: personagem.

20> Palmira Bastos em A viúvinha, s.d., Ilustração Portuguesa, 05-11-1906, p. 423, Pose: personagem. 21> Emília das Neves em várias personagens, Manuel de Macedo (des.), Caetano Alberto (grav.), Ocidente, 1102-1884, p. 36, Hemeroteca Digital, Pose: personagem. 22> Palmira Bastos, s.d., fot. não identificado, TNDMII, Pose: personagem

23> Maria Alice, s.d., Fotografia Brasil, TNDMII, Sob o signo do cinema/ vedetismo.

24> Beatriz Costa, s.d., fot. não identificado, MNT, Sob o signo do cinema/ vedetismo.

$25|27| 28$ > Beatriz Costa, s.d., fot. Silva Nogueira, MNT, Sob o signo do cinema/ vedetismo.

26> Beatriz Costa, s.d., fot. não identificado, MNT, Sob o signo do cinema/ vedetismo.
29> Alma Flora, 1959, fot. Artur Costa, MNT, Sob o signo do cinema/ vedetismo.

30> Mariana Vilar, s.d., fot. Silva Nogueira, MNT, civil oficial.

31> Mercedes Blasco, s.d., col. postais "Actores", 75 TNDMII, civil oficia

32> Palmira Bastos, s.d., fot. não identificado, TNDMII, civil oficial.

33> Adelina e Aura Abranches, s.d., fot. Portugália, MNT, civil informal.

34> Amélia Rey Colaço, Mariana Rey Monteiro, s.d fot. não identificado, MNT, civil informal.

35> Laura Alves, s.d., fot. não identificado, MNT, civil informal.

$36>$ Irene Cruz, s.d., fot. não identificado, MNT civil informal.

37> Eunice Muñoz (Prémio da Imprensa), 1964, fot. Armando Serôdio, AML, Presença na sociedade. 38> Adelina e Aura Abranches (funeral D. João da Câmara), 1908, fot. Joshua Benoliel, AML, Presença na sociedade

39> António de Oliveira Salazar, Amélia Rey Colaço 1965, fot. não identificado, MNT, Presença na sociedade.

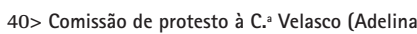
Abranches, Luiza Satanela, ..), s.d. (1926?) fot. não identificado, TNDMII, Presença na sociedade. 


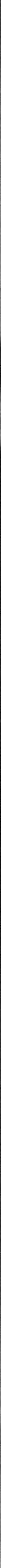




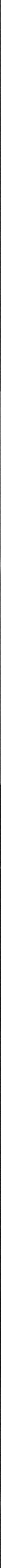




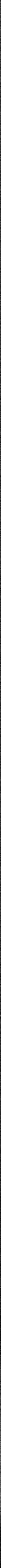



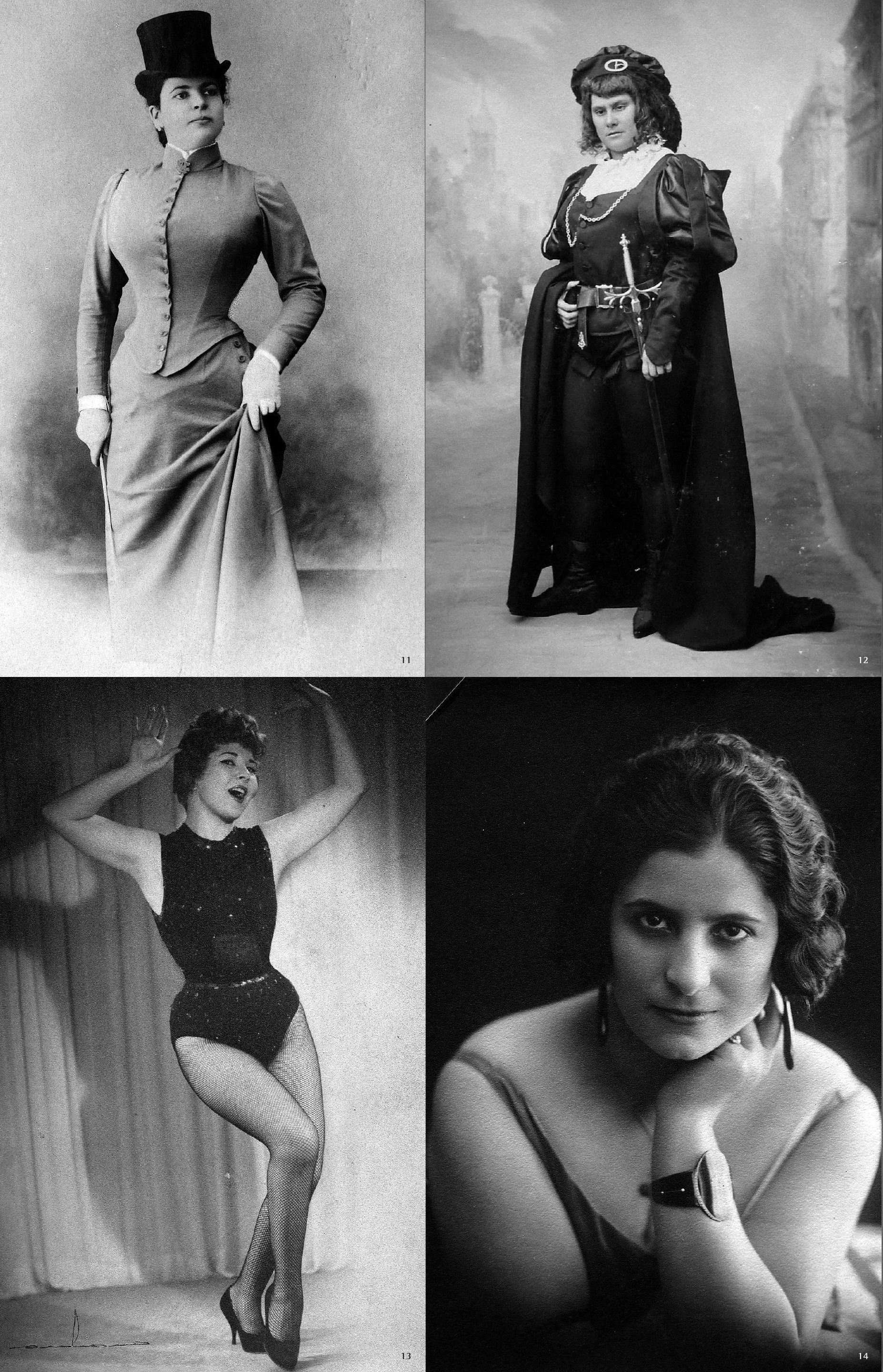


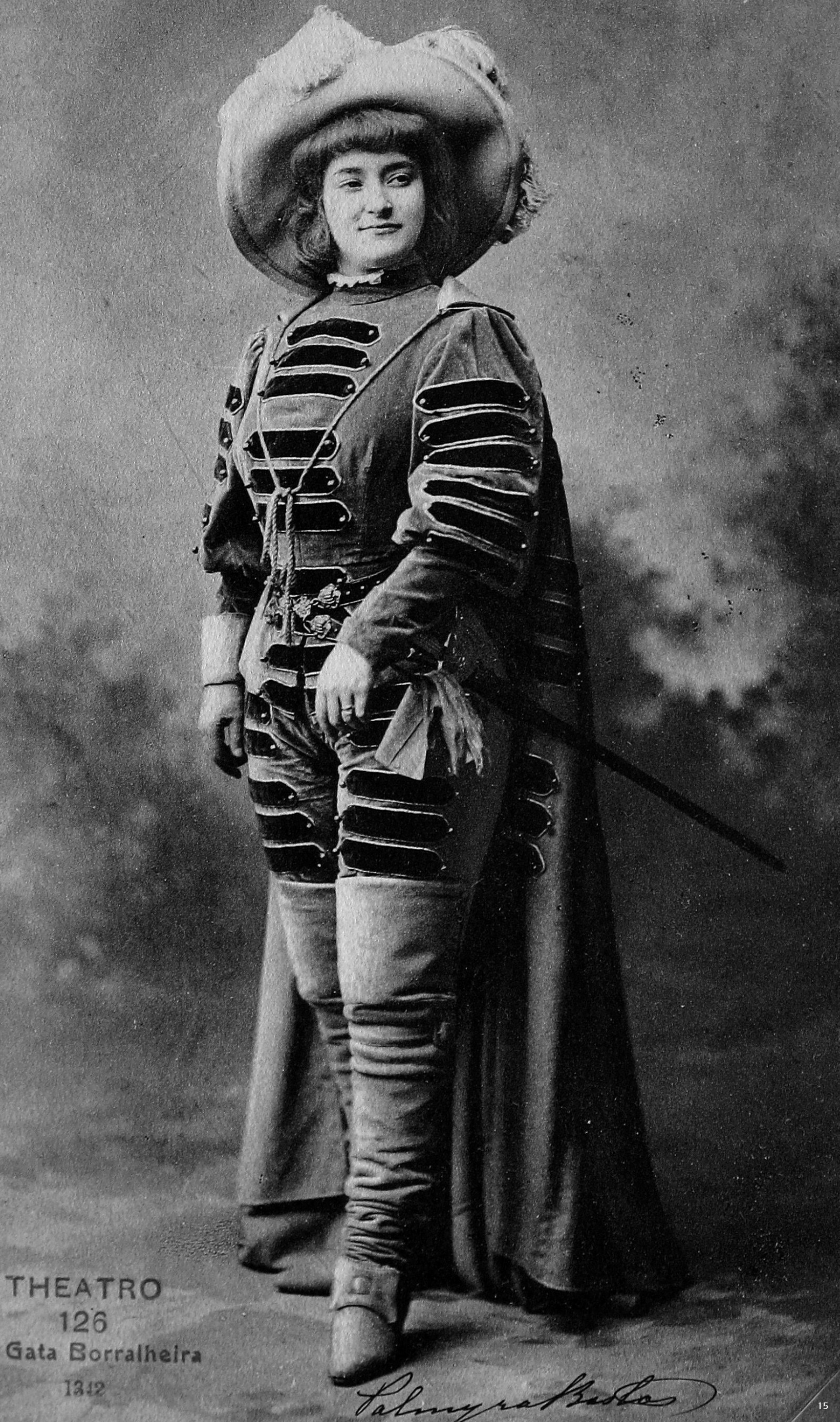



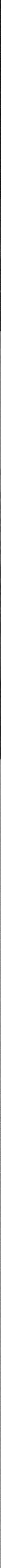
, 1. $1\left(\begin{array}{ll}3 & \\ 4 & 3\end{array}\right)$

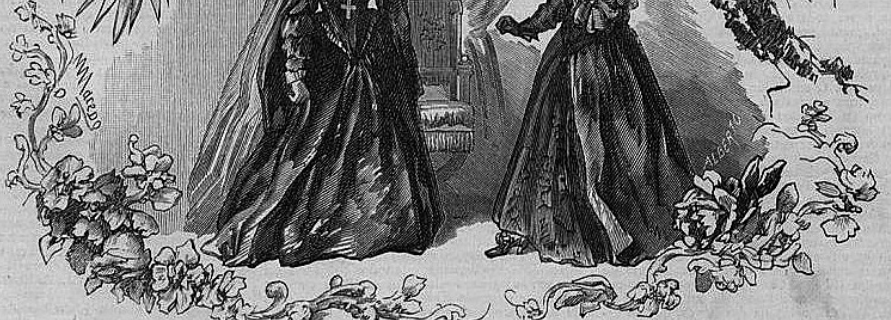




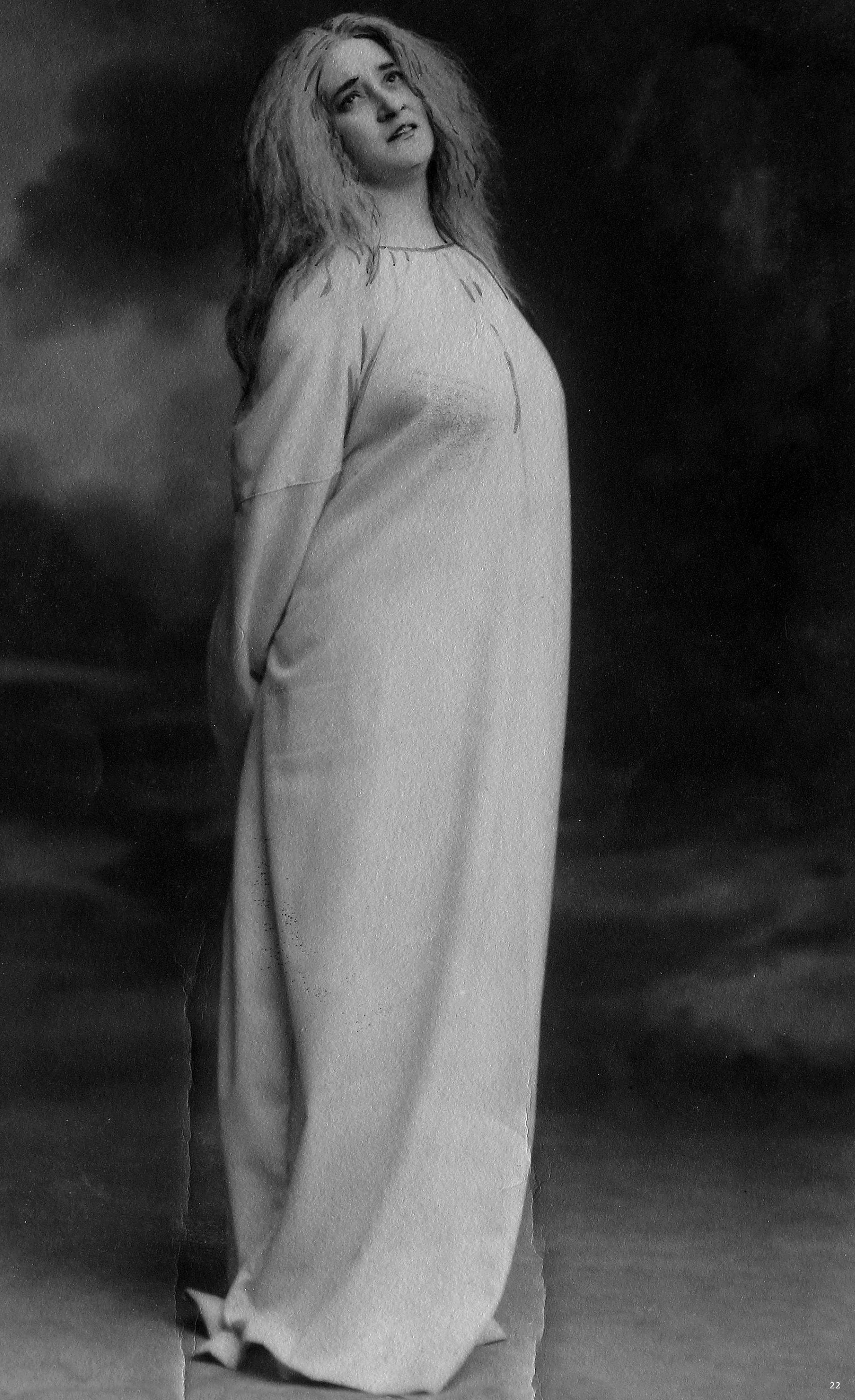



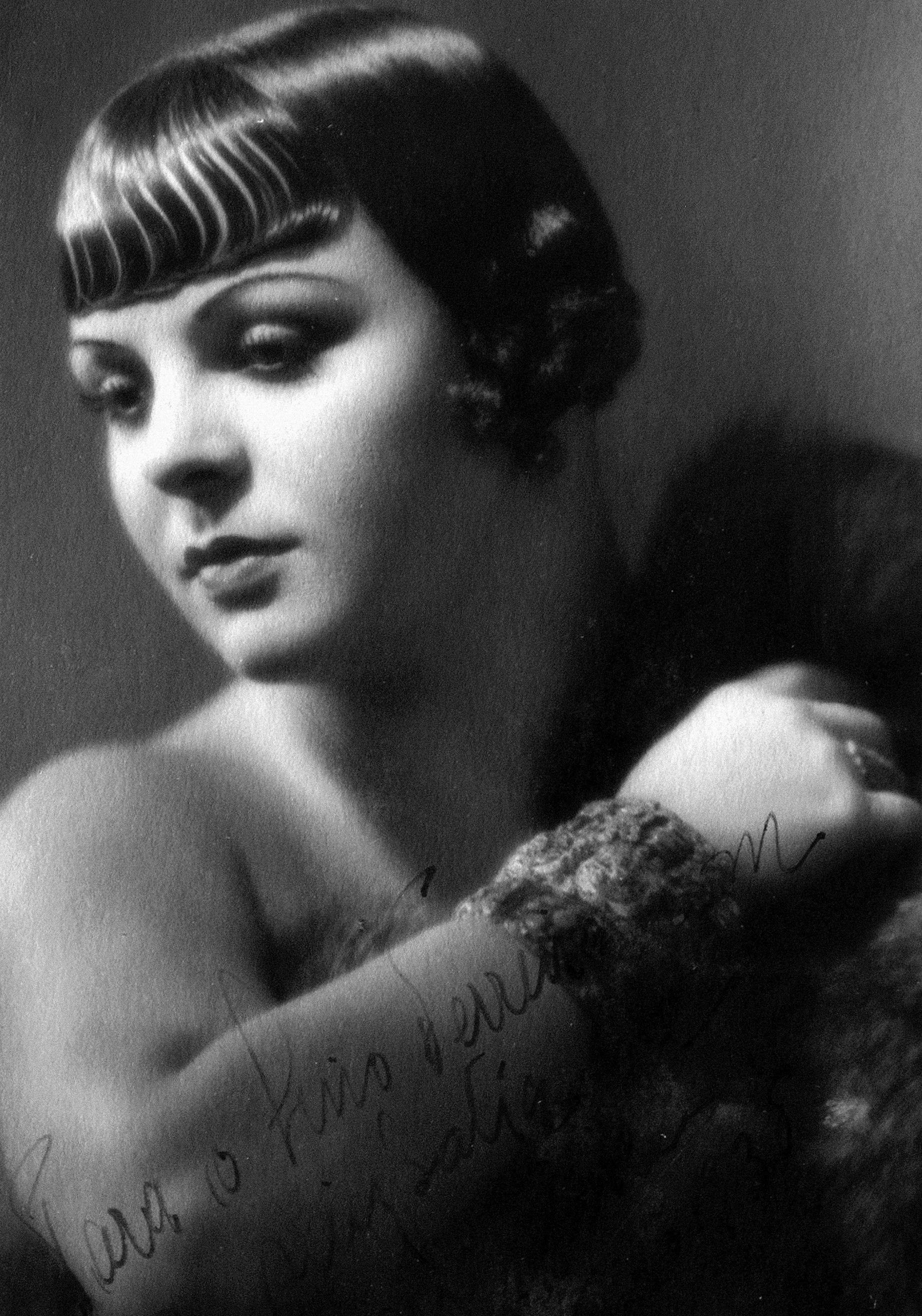

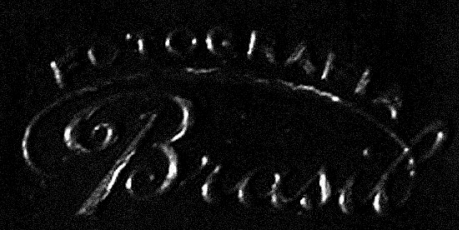




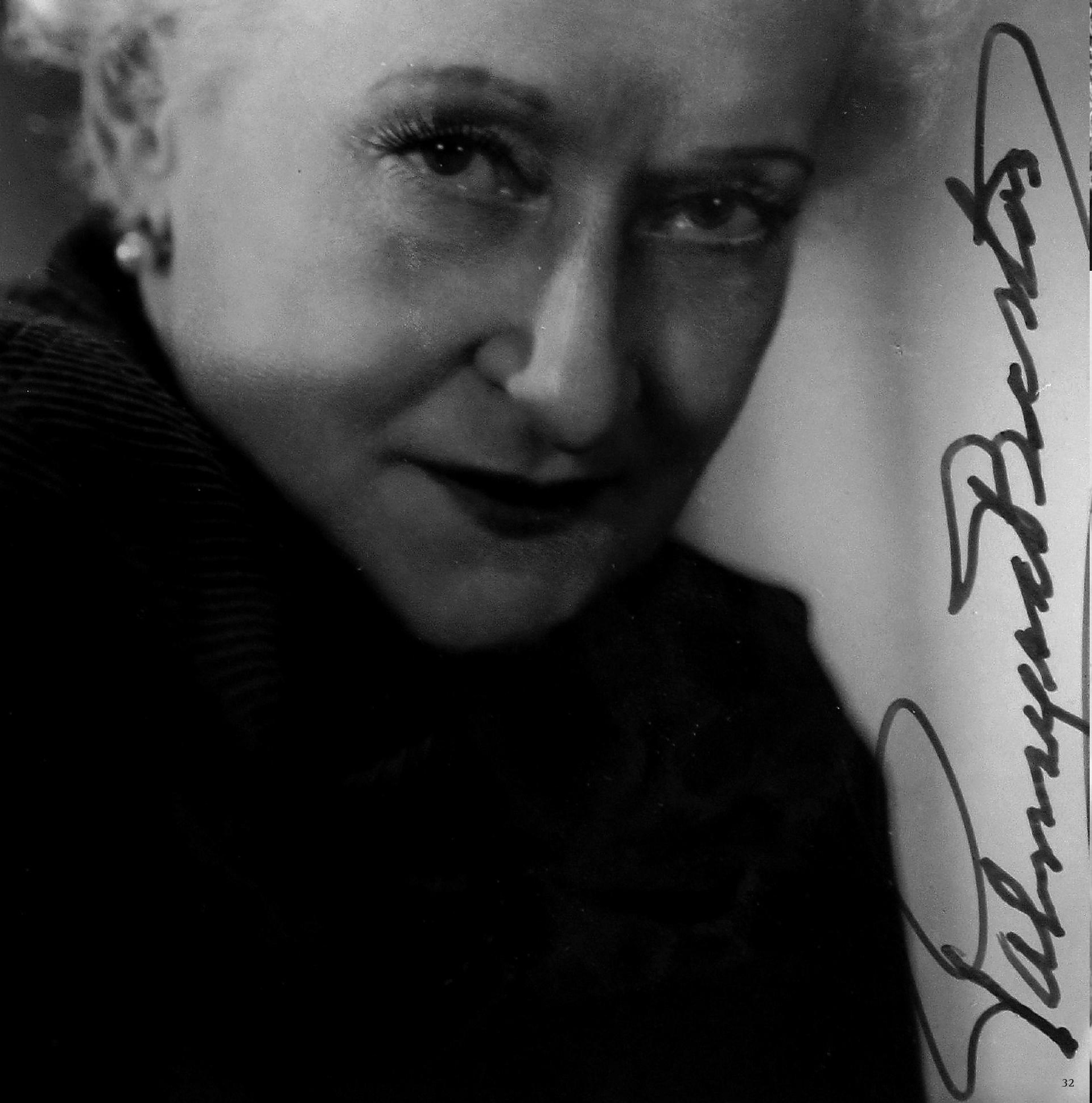




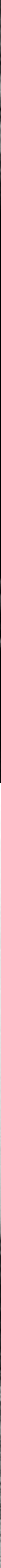




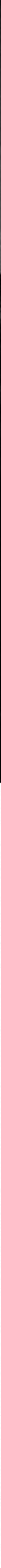

